\title{
Apatinib promotes apoptosis of the SMMC-7721 hepatocellular carcinoma cell line via the PI3K/Akt pathway
}

\author{
HUA ZHANG ${ }^{1}$, YUMEI CAO ${ }^{2}$, YURU $\mathrm{CHEN}^{3},{\text { GUANGXI } \mathrm{LI}^{2} \text { and HANSHU YU }}^{4}$ \\ ${ }^{1}$ Department of Interventional Radiology, Heze Municipal Hospital; ${ }^{2}$ Heze Municipal Hospital; \\ ${ }^{3}$ Department of Oncology, Heze Municipal Hospital; ${ }^{4}$ Department of Pediatrics, \\ Heze Medical College, Heze, Shandong 274000, P.R. China
}

Received July 24, 2017; Accepted January 9, 2018

DOI: $10.3892 / \mathrm{ol} .2018 .8031$

\begin{abstract}
The present study investigated the inhibitory effects of apatinib on the proliferation of the SMMC-7721 hepatocellular carcinoma cell line to explore the possible mechanism. The MTT assay was used to detect the inhibitory effects of the different concentrations of apatinib on the proliferation of SMMC-7721 cells. Annexin V/PI double staining was performed to investigate the effects of apatinib on the apoptosis of SMMC-7721 cells. Expression of the apoptosis-related genes $\mathrm{Bcl}-2, \mathrm{Bax}$ and caspase-9 after apatinib treatment was detected by reverse transcription-quantitative PCR (RT-qPCR) and western blot analysis Expression of the PI3K, p-PI3K, Akt and p-Akt proteins after apatinib treatment was detected using western blot analysis. The MTT results showed that apatinib inhibited the in vitro proliferation of SMMC-7721 cells. Annexin V/PI double staining showed that apatinib induced the apoptosis of SMMC-7721 cells in a concentration-dependent manner. Results of RT-qPCR and western blot analysis showed that apatinib was able to induce the expression of pro-apoptotic genes Bax and caspase-9 and inhibited the expression of anti-apoptotic gene $\mathrm{Bcl}$-2. In addition, the western blot analysis revealed that $\mathrm{p}-\mathrm{PI} 3 \mathrm{~K}$ and $\mathrm{p}$-Akt was significantly decreased following apatinib treatment, while no significant differences were found in the total protein levels of PI3K and Akt. The results of the present show that apatinib is capable of promoting the apoptosis of SMMC-7721 cells by inhibiting the PI3K/Akt signal transduction pathway, upregulating the expression of pro-apoptotic genes Bax and caspase-9, and downregulating the expression level of the anti-apoptotic gene $\mathrm{Bcl}-2$.
\end{abstract}

Correspondence to: Dr Hua Zhang, Department of Interventional Radiology, Heze Municipal Hospital, 2888 Caozhou Road, Heze, Shandong 274000, P.R. China

E-mail: z426u2@163.com

Key words: apatinib, hepatocellular carcinoma cell line SMMC-7721, apoptosis, PI3K/Akt

\section{Introduction}

Primary hepatocellular carcinoma is a common type of malignant tumor in the digestive system with the characteristics of high incidence, rapid progression and high mortality $(1,2)$. The occurrence and development of hepatocellular carcinoma is very complex with various genes and signaling transduction pathways involved, and the pathogenesis remains unclear (3). At present, the main clinical treatment of hepatocellular carcinoma is surgery. However, the early clinical symptoms of hepatocellular carcinoma are not obvious, which in turn leads to misdiagnosis. Therefore, most hepatocellular carcinoma patients are at an advanced stage at the time of diagnosis, and approximately $90 \%$ of patients no longer have the option of surgical resection, leading to the utilization of radiotherapy and chemotherapy $(4,5)$.

The phosphatidylinositol 3-kinase/protein kinase B pathway (PI3K/Akt) can affect the normal physiological activity of cells. Findings of previous studies have shown that the abnormal activation of the PI3K/Akt signaling pathway plays pivotal roles in the occurrence and development of breast, ovarian, gastric, and lung cancers and other malignant tumors (6-9). In addition, the PI3K/Akt signaling pathway plays an important role in the development and progression of hepatocellular carcinoma, and activation of the PI3K/Akt signaling pathway can affect the proliferation, invasion and apoptosis of hepatocellular carcinoma cells (10).

Apatinib is an antitumor drug that is used for the clinical treatment of advanced gastric cancer (11). In addition, previous findings showed that apatinib has therapeutic effects on breast and non-small cell lung cancer, as well as other types of cancer (12-14). Apatinib can specifically bind to ATP binding sites of VEGFR-2 in tumor cells to block the downstream signaling transductions of $c$-Kit, Ret and $c$-Src genes, thereby inhibiting neovascularization in tumor tissues (15).

The aim of the present study was to investigate the inhibitory effects of apatinib on the proliferation of the SMMC-7721 human hepatocellular carcinoma cell line, and to investigate the effects of apatinib on the expression of apoptotic-related genes Bcl-2, Bax and caspase-9 and the PI3K/Akt signaling pathway-related proteins, and to explore the mechanism of the effects of apatinib on hepatocellular 
carcinoma in order to lay the foundation for the clinical treatment of hepatocellular carcinoma with apatinib.

\section{Materials and methods}

Materials. Materials used in the present study were: Apatinib and DMSO (Aladdin, Shanghai, China); SMMC-7721 hepatocellular carcinoma cell line (The Cell Bank of Type Culture Collection of Chinese Academy of Sciences, Shanghai, China); RPMI-1640 medium (Gibco Life Technologies, Carlsbad, CA, USA); MTT (Sigma-Aldrich; Merck KGaA, Darmstadt, Germany); Annexin V/PI apoptosis detection kit (Beyotime Institute of Biotechnology, Nantong, China); TRIzol, reverse transcription kit and RT-qPCR kit (all from Invitrogen, Carlsbad, CA, USA); primer synthesis (Takara Biotechnology Co., Ltd., Dalian, China); rabbit anti-human PIAK, rabbit anti-human pPI3K, rabbit anti-human Akt, rabbit anti-human pAkt, rabbit anti-human Bcl-2, rabbit anti-human Bax, rabbit anti-human caspase-9, and rabbit anti-human GAPDH primary antibodies, and HRP-labeled goat anti-rabbit secondary antibody (all from Proteintech Group, Inc., Wuhan, China).

Cell culture. SMMC-7721 cells were incubated with RPMI-1640 medium containing $100 \mathrm{U} / \mathrm{ml}$ penicillin, $100 \mu \mathrm{g} / \mathrm{ml}$ streptomycin and $10 \%$ fetal bovine serum (FBS) in an incubator $\left(37^{\circ} \mathrm{C}, 5 \% \mathrm{CO}_{2}\right)$. The cells were collected during the logarithm growth period, and digested with trypsin to produce single cell suspension. The cells were subjected to different treatments according to the experimental design.

MTT assay to detect SMMC-7721 cell proliferation. SMMC-7721 cells $\left(100 \mu 1,1 \times 10^{5} / \mathrm{ml}\right)$ were inoculated into 96-well plates and cultured $\left(37^{\circ} \mathrm{C}, 5 \% \mathrm{CO}_{2}\right)$ for $24 \mathrm{~h}$. Then, apatinib was added at a concentration of $0,0.5,1,2,4,8$ and $16 \mu \mathrm{mol} / \mathrm{l}$. After incubation for $48 \mathrm{~h}, 10 \mu \mathrm{l}$ of MTT solution $(5 \mathrm{mg} / \mathrm{ml})$ was added into each well, followed by incubation for $4 \mathrm{~h}$. Absorbance values (OD) at $570 \mathrm{~nm}$ were measured using a microplate reader (Model 680; Bio-Rad Laboratories, Inc., Hercules, CA, USA), and the inhibition rate of apatinib on cell proliferation was calculated using the formula: Inhibition rate $(\%)=(\mathrm{OD}$ value of experimental group - OD value of normal control group)/(OD value of normal control group) x $100 \%$.

Annexin V/PI double staining to detect apoptosis of SMMC-7721 cells. The cells were collected during the logarithm growth period. After digestion with $0.25 \%$ trypsin, the cells were inoculated into 6-well plates, and then randomly divided into the control and apatinib treatment groups (1, 2 and $4 \mu \mathrm{mol} / \mathrm{l})$. After treatment with apatinib for $48 \mathrm{~h}$, the cells were digested with $0.25 \%$ trypsin, followed by centrifugation at 3,000 x g for $10 \mathrm{~min}$ to collect cells. The cells were washed twice with phosphate-buffered saline (PBS) and $5 \mu \mathrm{l}$ Annexin $\mathrm{V}$ and $5 \mu \mathrm{l}$ PI were added and mixed gently, followed by incubation in the dark for $15 \mathrm{~min}$. Cell apoptosis was detected by flow cytometry (Becton-Dickinson, Franklin Lakes, NJ, USA).

RT-qPCR used to detect the expression of related genes in SMMC-7721 cells. After the process described, TRIzol reagent
Table I. Primer sequences used in RT-qPCR.

\begin{tabular}{ll}
\hline Genes & \multicolumn{1}{c}{ Primer sequences } \\
\hline Bcl-2 & F: 5'-TGGGATGCCTTTGTGGAAC-3' \\
& R: 5'-CATATTTGTTTGGGGCAGGTC-3' \\
Bax & F: 5'-TGCTACAGGGTTTCATCCAG-3' \\
& R: 5'-ATCCACATCAGCAATCATCC-3' \\
Caspase-9 & F: 5'-AGCCAGATGCTGTCCCATAC-3' \\
& R: 5'-CAGGAGACAAAACCTGGGAA-3' \\
GAPDH & F: 5'-GGAAAGCTGTGGCGTGAT-3' \\
& R: 5'-AAGGTGGAAGAATGGGAGTT-3'
\end{tabular}

F, forward; R, reverse.

was used to extract total RNA from each group of cells. Only the RNA samples with a ratio of A260/A280 between 1.8 and 2.0 were used for reverse transcription to synthesize cDNA. Primer sequences used in PCR reactions are listed in Table I. PCR reaction conditions were as follows: $94^{\circ} \mathrm{C}$ for $3 \mathrm{~min}$ followed by 30 cycles of $94^{\circ} \mathrm{C}$ for $30 \mathrm{sec}, 57^{\circ} \mathrm{C}$ for $30 \mathrm{sec}$ and $72^{\circ} \mathrm{C}$ for $1 \mathrm{~min}$. The experiment was repeated 3 times. The data were processed using $2^{-\Delta \Delta \mathrm{Cq}}$ method: $\Delta \mathrm{Cq}$ (target gene) $=$ target gene $\mathrm{Cq}$ - control gene $\mathrm{Cq} ; \Delta \Delta \mathrm{Ct}=\Delta \mathrm{Cq}$ (target gene) $-\Delta \mathrm{Cq}$ (standard value). Relative expression levels of Bax, caspase-9 and Bcl-2 were calculated according to endogenous control GAPDH.

Western blot analysis used to detect the expression-related proteins in SMMC-7721 cells. After the process described, the total protein was collected from each group of cells after cell lysis using RIPA cell lysate. Protein concentration was quantified, and protein samples were subjected to $10 \%$ SDS-PAGE electrophoresis, followed by transmembrane to PVDF membrane. The membranes were blocked with $5 \%$ skimmed milk, followed by incubation with primary antibodies of PI3K, pPI3K, Akt, pAkt, Bcl-2, Bax, caspase-9 and GAPDH $(1: 1,000)$ overnight at $4^{\circ} \mathrm{C}$. After washing with TBST for $30 \mathrm{~min}$, membranes were incubated with labeled secondary antibody (1:500) at room temperature for $2 \mathrm{~h}$. Color development was performed with ECL solution and the results were photographed. Images were analyzed using Image Lab 4.0.1 software, and the relative expression of each protein was normalized to endogenous control GAPDH.

Statistical analysis. Data are expressed as mean \pm standard deviation and processed by SPSS 17.0 (IBM, Corp., Armonk, NY, USA). Single factor analysis of variance was used to analyze the data. $\mathrm{P}<0.05$ was considered to indicate a statistically significant difference.

\section{Results}

Effects of apatinib on the proliferation of SMMC-7721 cells. MTT results showed that apatinib $(0.5,1,2,4,8$ and $16 \mu \mathrm{mol} / \mathrm{l}$ ) was able to inhibit the activity of SMMC-7721 cells in a dose-dependent manner (Fig. 1). For the following experiments, apatinib at the concentrations of 1,2 and $4 \mu \mathrm{mol} / 1$, 


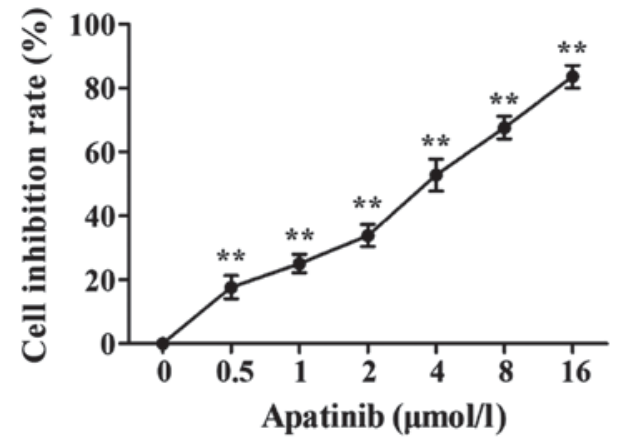

Figure 1. Inhibitory effect of different concentrations of apatinib on SMMC-7721 cells detected by MTT assay. Compared with control group, apatinitine significantly inhibited the proliferation of SMMC-7721 cells. ${ }^{* *} \mathrm{P}<0.01$, compared with the control group.

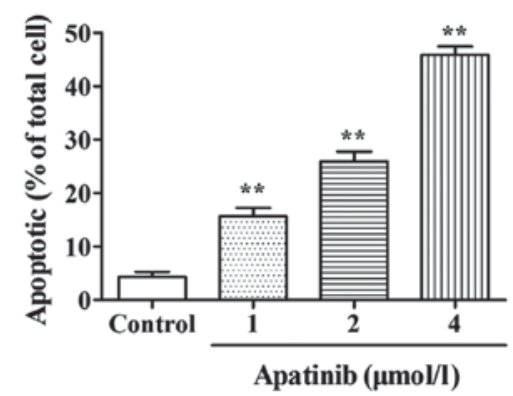

Figure 2. Effects of apatinib on the apoptosis of SMMC-7721 cells detected by AV/PI double staining. Compared with the blank control group, apatinib significantly promoted the apoptosis of SMMC-7721 cells. ${ }^{* *} \mathrm{P}<0.01$, compared with the control group.

which showed $50 \%$ inhibitory rate on cell proliferation were used, and the action time was $48 \mathrm{~h}$.

Effects of apatinib on the apoptosis of SMMC-7721 cells. Effect of apatinib on the apoptosis of SMMC-7721 cells was detected by AV/PI double staining. As shown in Fig. 2, compared with the control group, the cell apoptotic rate in the apatinib treatment groups were significantly increased $(\mathrm{p}<0.01)$, indicating that apatinib can significantly induce apoptosis of SMMC-7721 cells.

Effects of apatinib on the expression of apoptosis-related genes in SMMC-7721 cells. RT-qPCR and western blot results revealed that the expression levels of pro-apoptotic genes Bax and caspase-9 were significantly higher, and the expression level of the anti-apoptotic gene $\mathrm{Bcl}-2$ was significantly lower in cells treated with different concentrations of apatinib compared with the control group at the mRNA and protein levels (Figs. 3 and 4).

Effects of apatinib on PI3K/Akt pathway in SMMC-7721 cells. As shown in Fig. 5, compared with control group, levels of p-PI3K and p-Akt in cells treated with different concentrations of apatinib were significantly reduced. No significant differences were identified in the total protein levels of PI3K and Akt. Thus, apatinib can inhibit the phosphorylation of PI3K and Akt protein.
A

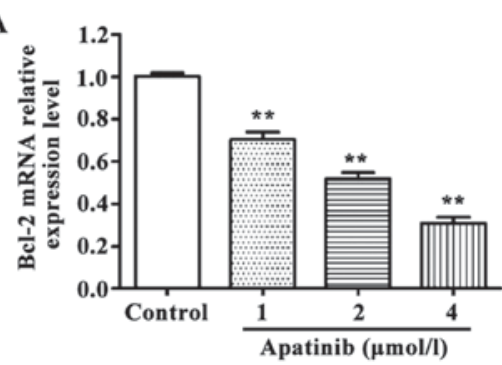

B
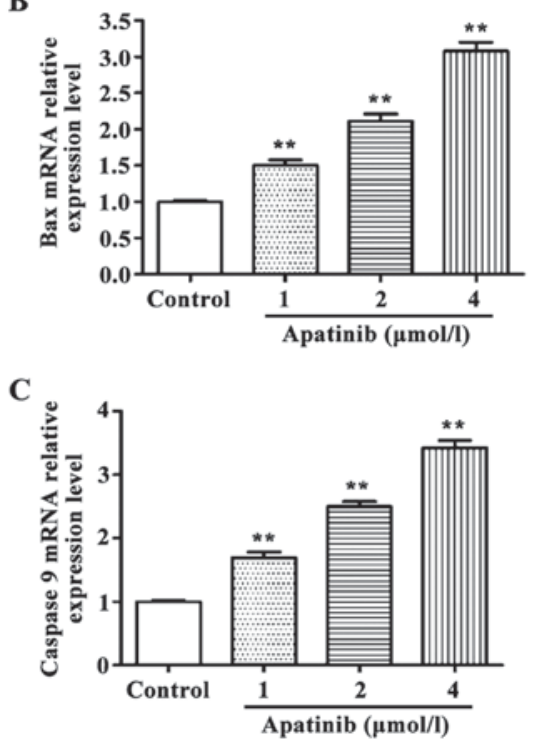

Figure 3. Effects of apatinib on the expression of apoptosis-related genes in SMMC-7721 cells detected by RT-qPCR. Compared with the control group, apatinib significantly increased the expression levels of Bax and caspase-9 mRNA and inhibited the expression of Bcl-2 mRNA in SMMC-7721 cells. ${ }^{* *} \mathrm{P}<0.01$, compared with control group.

A
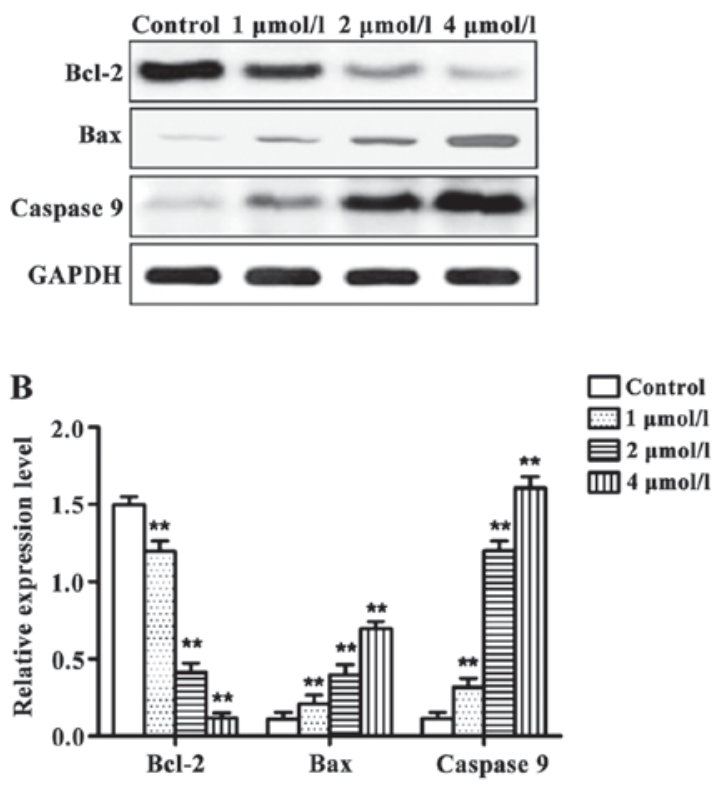

Figure 4. Effects of apatinib on the expression of apoptosis-related proteins in SMMC-7721 cells detected by western blot analysis. (A) Results of western blot analysis. (B) Relative expression levels of each protein. Compared with the control group, apatinib significantly increased the expression levels of Bax and caspase- 9 protein and inhibited the expression of $\mathrm{Bcl}-2$ protein in SMMC-7721 cells. ${ }^{* *} \mathrm{P}<0.01$, compared with the control group. 

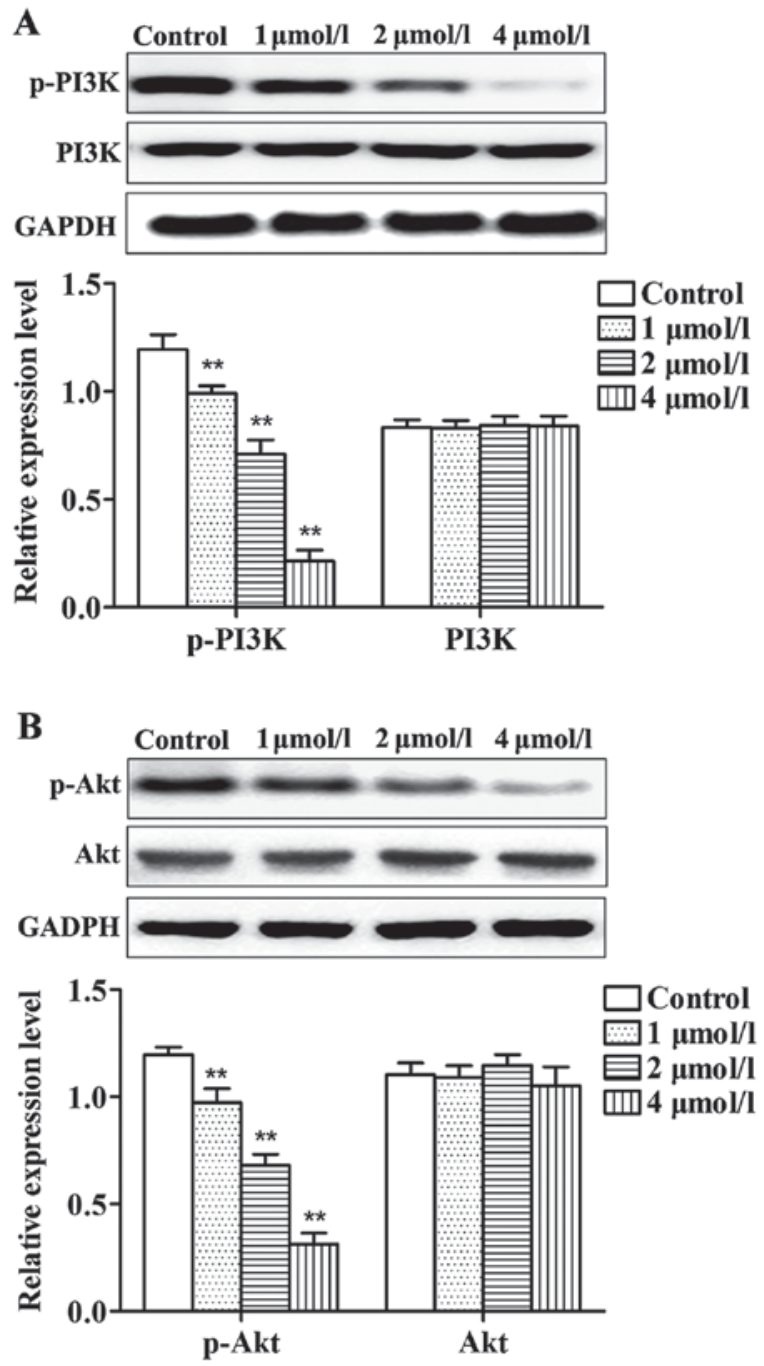

Figure 5. Effect of apatinib on the expression of PI3K, p-PI3K, Akt and p-Akt in SMMC-7721 cells detected using western blot analysis. (A) Levels of PI3K and p-PI3K protein. (B) Levels of Akt and p-Akt protein. Compared with the control group, levels of the p-PI3K and p-Akt apatinib treatment groups were significantly reduced, but total protein levels of PI3K and Akt were not significantly changed. ${ }^{* *} \mathrm{P}<0.01$, compared with the control group.

\section{Discussion}

In China, a large portion of the population is affected by hepatocellular carcinoma, which shows both a high incidence and mortality rate (16). At present, the preferred treatment is surgical resection. However, the early symptoms of hepatocellular carcinoma are not clear, and most patients are diagnosed with distant metastasis, which can only be treated with radiotherapy or chemotherapy (17). Apatinib, or N-[4-(1-cyanocyclopentyl) phenyl]-2-(4-pyridylmethyl) amino-3-pyridinecarboxamide methanesulfonate, is a new type of small molecule VEGFR-2 tyrosine kinase inhibitor that can be taken orally. Apatinib has been approved by the China Food and Drug Admistration to treat patients with recurrent advanced gastric adenocarcinoma and gastric-esophageal junction adenocarcinoma. In addition, the therapeutic effects of apatinib on non-small cell lung, breast, liver and rectal cancers are now being tested clinically (18-20).

PI3K is an important kinase of phosphatidylinositol and inositol. PI3K can be activated by receptor on cell surface to form $\mathrm{p}-\mathrm{PI} 3 \mathrm{~K}$, and $\mathrm{p}-\mathrm{PI} 3 \mathrm{~K}$ can activate Akt and other downstream effector to transduct the signals of various growth factors and cytokines to cells $(21,22)$. Phosphorylated Akt can act on proteins in Bcl-2 family and the caspase family to inhibit cell apoptosis, which in turn lead to excessive cell growth and proliferation (23). Studies have shown that PI3K and Akt were highly expressed in various types of tumor cells, and the activated PI3K/Akt pathway can promote the proliferation and invasion of tumor cells and induce resistance of tumor cells to chemotherapeutic drugs $(24,25)$.

As an anti-apoptotic protein, Bcl-2 plays a key role in the apoptotic signaling pathway. Bcl-2 can inhibit cell apoptosis and improve cell proliferation (26). As a pro-apoptotic protein, Bax has opposite functions to Bcl-2. Bax and Bcl-2 belong to the same family. Bax, not only antagonizes the inhibitory effects of Bcl-2 on cell apoptosis, but also directly promotes tumor cell apoptosis (27). Caspase-9 is a key factor in the mitochondrial apoptosis pathway. Activated caspase- 9 can further activate downstream caspase-3, which in turn leads to tumor cell apoptosis $(28,29)$.

In the present study, different concentrations of apatinib were used to treat SMMC-7721 cells for $48 \mathrm{~h}$. The MTT assay showed that apatinib significantly inhibited the proliferation of SMMC-7721 cells. Annexin V/PI double staining results showed that apatinib was able to induce the apoptosis of SMMC-7721 cells in a concentration-dependent manner. Results of RT-qPCR and western blot analysis showed that apatinib induced the expression of pro-apoptotic genes Bax and caspase- 9 and inhibited the expression of anti-apoptotic gene $\mathrm{Bcl}-2$, indicating that apatinib can induce tumor cell apoptosis. In this study, the possible involvement of the PI3K/Akt signaling pathway was also investigated. Western blot analysis revealed that apitatinib significantly reduced the levels of p-PI3K and p-Akt in SMMC-7721 cells, but showed no significant effect on total protein levels of PI3K and Akt. Similar results were found in a study carried out by Yin et al, that is, apatinib can induce the apoptosis of HCT-116 colon cancer cells by inhibiting the MAPK/Erk pathway, reducing the phosphorylation of p-ERK and p-AKT in the PI3K/Akt pathway, and inducing the expression of Bax and caspase-3 (30).

In conclusion, the present findings have shown that apatinib inhibited the proliferation and induced the apoptosis of human hepatocellular carcinoma cells possibly by inhibiting the PI3K/Akt signaling transduction pathway, upregulating the expression of Bax and caspase-9, and downregulating the expression of $\mathrm{Bcl}-2$.

\section{Acknowledgements}

Not applicable.

\section{Funding}

No funding was received.

\section{Availability of data and materials}

The datasets used and/or analyzed during the present study are available from the corresponding author on reasonable request. 


\section{Authors' contributions}

$\mathrm{HZ}$ and YCa analyzed and interpreted the patient data. HZ wrote the manuscript. YCh and HY collected the patient data and revised the manuscript for important intellectual content. $\mathrm{HZ}$ and GL contributed to the conception and design of the study. All authors read and approved the final manuscript.

\section{Ethics approval and consent to participate}

The study was approved by the Ethics Committee of Heze Municipal Hospital.

\section{Consent for publication}

Not applicable.

\section{Competing interests}

The authors declare that they have no competing interests.

\section{References}

1. Ferlay J, Soerjomataram I, Dikshit R, Eser S, Mathers C, Rebelo M, Parkin DM, Forman D and Bray F: Cancer incidence and mortality worldwide: Sources, methods and major patterns in GLOBOCAN 2012. Int J Cancer 136: E359-E386, 2015.

2. Ferlay J, Shin HR, Bray F, Forman D, Mathers C and Parkin DM: Estimates of worldwide burden of cancer in 2008: GLOBOCAN 2008. Int J Cancer 127: 2893-2917, 2010.

3. Gomaa AI, Khan SA, Toledano MB, Waked I and Taylor-Robinson SD: Hepatocellular carcinoma: Epidemiology, risk factors and pathogenesis. World J Gastroenterol 14 : 4300-4308, 2008

4. Zhang S, Yue M, Shu R, Cheng H and Hu P: Recent advances in the management of hepatocellular carcinoma. J BUON 21 307-311, 2016 .

5. Ling CQ, Liu Q, Li DT, Yue XQ, Hou FG, Zhu DZ, Yu CQ, Chen Z, Zhai XF and Yu Y: Study of a qualitative diagnostic criterion for basic syndromes of traditional Chinese medicine in patients with primary liver cancer. Zhong Xi Yi Jie He Xue Bao 3: 95-98, 2005 (In Chinese).

6. Wu P, Liu T and Hu Y: PI3K inhibitors for cancer therapy: What has been achieved so far? Curr Med Chem 16: 916-930, 2009.

7. Mabuchi S, Kuroda H, Takahashi R and Sasano T: The $\mathrm{PI} 3 \mathrm{~K} / \mathrm{AKT} / \mathrm{mTOR}$ pathway as a therapeutic target in ovarian cancer. Gynecol Oncol 137: 173-179, 2015.

8. Yu HY, Kim SO, Jin CY, Kim GY, Kim WJ, Yoo YH and Choi YH: $\beta$-lapachone-induced apoptosis of human gastric carcinoma AGS cells is caspase-dependent and regulated by the PI3K/Akt pathway. Biomol Ther (Seoul) 22: 184-192, 2014.

9. Fu YL, Zhang QH, Wang XW and He H: Antidiabetic drug metformin mitigates ovarian cancer SKOV3 cell growth by triggering G2/M cell cycle arrest and inhibition of m-TOR/PI3K/Akt signaling pathway. Eur Rev Med Pharmacol Sci 21: 1169-1175, 2017.

10. Engelman JA: Targeting PI3K signalling in cancer: Opportunities, challenges and limitations. Nat Rev Cancer 9: 550-562, 2009.

11. Geng R and Li J: Apatinib for the treatment of gastric cancer. Expert Opin Pharmacother 16: 117-122, 2015.

12. Roviello G, Ravelli A, Polom K, Petrioli R, Marano L, Marrelli D, Roviello F and Generali D: Apatinib: A novel receptor tyrosine kinase inhibitor for the treatment of gastric cancer. Cancer Lett 372: 187-191, 2016.

13. Zhang H: Apatinib for molecular targeted therapy in tumor. Drug Des Devel Ther 9: 6075-6081, 2015

14. Mi YJ, Liang YJ, Huang HB, Zhao HY, Wu CP, Wang F, Tao LY, Zhang CZ, Dai CL, Tiwari AK, et al: Apatinib (YN968D1) reverses multidrug resistance by inhibiting the efflux function of multiple ATP-binding cassette transporters. Cancer Res 70: 7981-7991, 2010
15. Tian S, Quan H, Xie C, Guo H, Lü F, Xu Y, Li J and Lou L: YN968D1 is a novel and selective inhibitor of vascular endothelial growth factor receptor-2 tyrosine kinase with potent activity in vitro and in vivo. Cancer Sci 102: 1374-1380, 2011

16. El-Serag HB and Rudolph KL: Hepatocellularcarcinoma: Epidemiology and molecular carcinogenesis. Gastroenterology 132: 2557-2576, 2007.

17. Frau M, Biasi F, Feo F and Pascale RM: Prognostic markers and putative therapeutic targets for hepatocellular carcinoma. Mol Aspects Med 31: 179-193, 2010.

18. Li J, Qin S, Xu J, Guo W, Xiong J, Bai Y, Sun G, Yang Y, Wang L, Xu N, et al: Apatinib for chemotherapy-refractory advanced metastatic gastric cancer: Results from a randomized, placebo-controlled, parallel-arm, phase II trial. J Clin Oncol 31: 3219-3225, 2013

19. Fan M, Zhang J, Wang Z, Wang B, Zhang Q, Zheng C, Li T, Ni C, Wu Z, Shao Z, et al: Phosphorylated VEGFR2 and hypertension: Potential biomarkers to indicate VEGF-dependency of advanced breast cancer in anti-angiogenic therapy. Breast Cancer Res Treat 143: 141-151, 2014.

20. Ohtsu A, Shah MA, Van Cutsem E, Rha SY, Sawaki A, Park SR, Lim HY, Yamada Y, Wu J, Langer B, et al: Bevacizumab in combination with chemotherapy as first-line therapy in advanced gastric cancer: A randomized, double-blind, placebo-controlled phase III study. J Clin Oncol 29: 3968-3976, 2011.

21. Xia M, Tong JH, Ji NN, Duan ML, Tan YH and Xu JG: Tramadol regulates proliferation, migration and invasion via PTEN/PI3K/AKT signaling in lung adenocarcinoma cells. Eur Rev Med Pharmacol Sci 20: 2573-2580, 2016.

22. Carnero A, Blanco-Aparicio C, Renner O, Link W and Leal JF: The PTEN/PI3K/AKT signalling pathway in cancer, therapeutic implications. Curr Cancer Drug Targets 8: 187-198, 2008.

23. Gondi CS, Kandhukuri N, Dinh DH, Gujrati M and Rao JS: Down-regulation of UPAR and UPA activates caspase-mediated apoptosis and inhibits the PI3K/AKT pathway. Int J Oncol 31: 19-27, 2007.

24. Roberts LR and Gores GJ: Hepatocellular carcinoma: Molecular pathways and new therapeutic targets. Semin Liver Dis 25: 212-225, 2005

25. Zhao JG, Zhang L, Xiang XJ, Yu F, Yu F, Ye WL, Wu DP, Wang JF and Xiong JP: Erratum: Amarogentin secoiridoid inhibits in vivo cancer cell growth in xenograft mice model and induces apoptosis in human gastric cancer cells (SNU-16) through G2/M cell cycle arrest and PI3K/Akt signalling pathway. J BUON 21: 1332, 2016

26. Packham G and Cleveland JL: c-Myc and apoptosis. Biochim Biophys Acta 1242: 11-28, 1995.

27. Brady HJ and Gil-Gómez G: Bax. The pro-apoptotic Bcl-2 family member, Bax. Int J Biochem Cell Biol 30: 647-650, 1998.

28. Schroeder CP, Kadara H, Lotan D, Woo JK, Lee HY, Hong WK and Lotan R: Involvement of mitochondrial and Akt signaling pathways in augmented apoptosis induced by a combination of low doses of celecoxib and $\mathrm{N}$-(4-hydroxyphenyl) retinamide in premalignant human bronchial epithelial cells. Cancer Res 66: 9762-9770, 2006.

29. Agarwal S, Achari C, Praveen D, Roy KR, Reddy GV and Reddanna P: Inhibition of $12-\mathrm{LOX}$ and $\mathrm{COX}-2$ reduces the proliferation of human epidermoid carcinoma cells (A431) by modulating the ERK and PI3K-Akt signalling pathways. Exp Dermatol 18: 939-946, 2009.

30. Yin L, Wang J, Huang FC, Zhang YF, Xu N, Wen ZQ, Li WL and Dong J: Inhibitory effect of apatinib on HCT-116 cells and its mechanism. Nan Fang Yi Ke Da Xue Xue Bao 37: 367-372, 2017 (In Chinese).

This work is licensed under a Creative Commons Attribution-NonCommercial-NoDerivatives 4.0 International (CC BY-NC-ND 4.0) License. 